baf- $\odot$

Proceedings of the Berner

Altorientalisches

Forum

ISSN 2504-2076

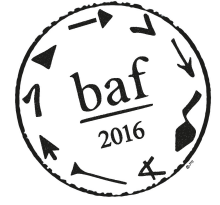

Abstract

Marta Pallavidini, University of Pavia

DOI: http://dx.doi.org/10.22012/baf.2016.11

\title{
Political Metaphors in Hittite Diplomatic and Historiographic Texts
}

Research topic: In the Hittite historiographic and diplomatic texts some concepts are formulated metaphorically. In particular, we can find metaphors based on expressions of motion; involving body parts; recalling the comparison between a person and an animal; describing the concepts of life and death; concerning the lexicon of the family and relatives.

Theoretical approach: These metaphors are to be considered as expressions of a system of thinking, i.e. as conceptual metaphors (Lakoff - Johnson 1980).

Research questions: Which metaphors are attested? How are they structured? How do they dependent on context, language, and/or genre? Which metaphors are of Hittite origin? Which functions do they have?

Research goals: Identification, classification and description of the metaphors; analysis of their functions; description of the changes in their use in relation to the genre and through time.

Method: the Metaphor Identification Procedure (MIP) of the Praggelejaz Group. 